\title{
Characterological Correlates of Selfie Taking Behavior
}

\author{
Eric Gilliland, Mark J. Kiss, Melanie A. Morrison, Todd G. Morrison* \\ Department of Psychology, University of Saskatchewan, Saskatoon, Canada \\ Email: ^Todd.Morrison@usask.ca
}

How to cite this paper: Gilliland, E., Kiss, M. J., Morrison, M. A., \& Morrison, T. G. (2018). Characterological Correlates of Selfie Taking Behavior. Psychology, 9, 1530-1545. https://doi.org/10.4236/psych.2018.96092

Received: May 9, 2018

Accepted: June 26, 2018

Published: June 29, 2018

Copyright $\odot 2018$ by authors and Scientific Research Publishing Inc. This work is licensed under the Creative Commons Attribution International License (CC BY 4.0).

http://creativecommons.org/licenses/by/4.0/

\section{c) (i) Open Access}

\begin{abstract}
Few researchers have examined selfie taking behavior. To address this gap, 235 participants (age 18 - 60) completed an online questionnaire assessing a variety of psychological factors, personality traits, and selfie taking activities (i.e., frequency of selfies posted to social networking sites [SNSs], time spent editing selfies, and number of selfie takes prior to posting). A number of statistically significant correlations emerged. For example, participants' levels of neuroticism, social physique anxiety, body-related shame, and concern about physical appearance correlated positively with the amount of time spent editing selfies. As well, group comparisons between selfie $(n=193)$ and non-selfie takers $(n=42)$ suggest that the former exhibit higher levels of certain facets of vanity. The implications of these findings and directions for future research are outlined.
\end{abstract}

\section{Keywords}

Social Media, Vanity, Neuroticism, Body Image, Shame, Guilt

\section{Introduction}

The advent of the Internet coupled with interactive technology such as smart phones and tablets has facilitated a heightened level of interconnectivity via digital social media. Numerous methods exist for users to interact with each other online; however, one of the most popular involves the sharing and publishing of selfies (i.e., digital photographs taken of oneself by oneself [sometimes in the company of others]). A recent survey found that $55 \%$ of 18 to 33 year-old individuals residing in the United States have posted a selfie online, and $81 \%$ of this age group at least know what a selfie is (Pew Research Center, 2014). Previous research indicates that individuals take selfies as a form of self-presentation, communication, attention seeking, and appearance feedback from peers and 
strangers (Baiocco et al., 2017; Katz \& Crocker, 2015). The growing ubiquity of the selfie may be due to its increasingly common depictions within various forms of media (e.g., reality television, movies, and popular music). Despite its pervasiveness, little is known about the average selfie taker in terms of characterological facets such as personality traits and body image. Therefore, the purpose of the current study is to address this gap in understanding. Prior to doing so, a brief review of the relevant literature on personality, body image and use of social media will be provided.

\subsection{Personality}

Personality is a broad concept encompassing many stable facets of individual and interpersonal differences. The most widely acknowledged and studied conceptualization of personality is the Five Factor or "Big Five" Model (Costa \& McCrae, 1992; Goldberg, 1999; Goldberg et al., 2006; McCrae \& Costa, 1997). Recently, this model has been used extensively by researchers investigating photo uploading personality characteristics of social networking site (SNS) users (e.g., Amichai-Hamburger \& Vinitzky, 2010; Eftekhar, Fullwood, \& Morris, 2014). To date, Extraversion and Neuroticism have emerged as having the strongest association with photo-related activities on social media. For instance, positive correlations have been documented between these two personality traits and the number of photos posted on SNSs (Amichai-Hamburger \& Vinitzky, 2010; Eftekhar et al., 2014). Furthermore, SNS users evidencing greater levels of Neuroticism posted more self-photos; self-photos, in this case, included pictures fitting within the definition of selfies as well as a broad range of other user generated pictorial content (Amichai-Hamburger \& Vinitzky, 2010).

Correlations between general photo uploading activity on SNSs and the personality dimensions of Agreeableness, Conscientiousness, and Openness are inconsistent (e.g., Eftekhar et al., 2014; Ross et al., 2009). To illustrate: Amichai-Hamburger and Vinitzky (2010) found a statistically significant positive association between individuals' level of agreeableness and photo uploading on SNSs whereas Eftekhar and colleagues (2014) identified no such relationship. Conscientiousness also seems to exhibit a mixed association with photo-related activity. Specifically, a non-significant correlation was observed between this variable and photo-uploading (Amichai-Hamburger \& Vinitzky, 2010; Lee, Ahn, \& Kim, 2014) whereas statistically significant correlations were obtained when other activities such as photo organization were examined (Eftekhar et al., 2014).

Recent investigations have begun to explore the relationship between the Big Five and various selfie behaviors. In line with previous literature on SNSs and general photo-related activity, Extraversion has been consistently linked to larger numbers of selfies being posted online (Guo et al., 2018; Kim \& Chock, 2017; Sorokowska et al., 2016). The preliminary work of Kim and Chock (2017) provides the only other data on Big Five correlates of selfie behaviors. They found that Neuroticism was not significantly correlated with aspects of selfie taking 
such as the number of selfies posted on SNSs and frequency of editing selfies. Additionally, Agreeableness exhibited a positive relationship with posting different types of selfies (i.e., higher tendency to post group selfies); Conscientiousness was negatively associated with editing frequency; and Openness was not correlated to any of the identified selfie behaviors in their study. Researchers have also investigated selfie behavior using the HEXCO (Ashton \& Lee, 2009), an expanded and modified version of the Big Five. The primary difference between the two measures is the removal of the Neuroticism dimension in lieu of two additional dimensions: Emotionality and Honesty/Humility. Emotionality refers to a person's tendency to be vulnerable, sentimental and fearful whereas low Emotionality would indicate fearlessness, detachment and toughness. According to Ashton and Lee (2009), the Emotionality dimension is akin to Big Five's Neuroticism, but is less judgmental (i.e., it does not describe an individual's personality using negative terminology). Honesty/Humility describes fairness, sincerity, and unassuming behaviors. In comparison, those low in Honesty/Humility evidence antisocial behaviors and unethical behavior. In a study evaluating the personalities of selfie taking in 13 to 30 year-old participants, researchers measured the frequency of posting selfies (solo, group, or partner) using the HEXCO dimensions (Baiocco et al., 2017). Lower Honesty/Humility, lower Conscientiousness, higher Emotionality and higher Extraversion significantly predicted solo selfies and group selfies. While these findings provide an initial view of the relationship between selfies and personality, more research is needed to solidify this pattern of results.

As previously discussed, Narcissism appears to be a crucial personality factor that has been associated with certain general photo activity on SNSs. This trait is characterized by a highly inflated sense of self and a strong need for admiration from others (Pincus et al., 2009). Relevant studies suggest that narcissism correlates positively with the number of online photo uploads (Barry et al., 2017; Mehdizadeh, 2010; Ong et al., 2011; Ryan \& Xenos; 2011; Sung, Lee, Kim, \& Choi, 2016), photos containing the self (Amichai-Hamburger \& Vinitzky, 2010) and the propensity to engage in editing behaviors (e.g., posing and using editing software) prior to uploading photos (Mehdizadeh, 2010). A growing body of literature shows a similar pattern of results between selfie taking behavior and narcissism. Namely, a greater number of selfies posted on SNSs (Fox \& Rooney, 2015; McCain et al., 2016, Weiser, 2015) and more frequent selfie editing (Fox \& Rooney, 2015; Kim \& Chock, 2017) have been linked to higher degrees of narcissism.

Vanity is generally considered a facet of narcissism (e.g., Narcissistic Personality Inventory; Raskin \& Terry, 1988); one that pertains specifically to physical appearance (Netemeyer, Burton, \& Lichtenstein, 1995; Raskin \& Terry, 1988). Given that selfies focus on how individuals look, it seems reasonable to propose that vanity might be a strong correlate of selfie taking activity. Yet, there is a minimal amount of research examining the relationship between selfies and vanity. 
To date, only one study has analyzed vanity independently of the other facets of narcissism (Sorokowski et al., 2015). These researchers found that, among their all-male sample, higher endorsement of vanity was linked to the posting of more types of selfies (e.g., solo, with a partner, etc.) on SNSs.

\subsection{Body Image}

While body image is a multidimensional construct (Pruzinsky \& Cash, 2002), for the purpose of the current study, it is operationalized as an individual's perception of their body. The largely negative impact of media on body image has been well established in the literature (see Tiggemann [2014] for a review). There also is a growing corpus of research indicating the importance of SNSs in the communication of idealized body images as these platforms rise in prominence and membership over traditional media. Within this area of research, there seem to be analogous findings on the negative impact of SNSs on body image (see Holland \& Tiggemann [2016] for a review). Notably, as levels of photo activity on SNSs increase so, too, do negative perceptions of one's appearance. Given these associations, body image seems to be an important variable to consider when examining selfie taking.

One possible response to body image concerns is social physique anxiety (SPA), which typically manifests from the anticipation of having one's body negatively evaluated by others. SPA has been linked to several different psychological factors. For example, SPA correlates negatively with self-esteem, and positively with the drive for muscularity in men and the drive for thinness in women (Brunet, Sabiston, Dorsch, \& McCreary, 2010). SPA also has been linked with efforts to modify one's appearance through dieting and physique concealment (see Sabiston, Pila, Pinsonnault-Bilodeau, \& Cox, [2014] for a review). To date, no studies have examined the relationship between SPA and photo activity on SNSs.

Body-related guilt and shame are other possible responses to body image concerns. Guilt arises from behaviors that fail to achieve a goal whereas shame results from more global negative self-evaluations (e.g., Castonguay, Sabiston, Crocker, \& Mack, 2014). Shame typically elicits the desire to hide or escape (Tangney \& Tracy, 2012), while guilt has been linked to a wide range of reparative behaviors (Baumeister, Stillwell, \& Heatherton, 1994; Silfver, 2007). Within the realm of appearance-related guilt, enhanced physical activity may constitute one type of reparation (Castonguay, Pila, Wrosch, \& Sabiston, 2015; Castonguay et al., 2014). Again, to date, no researchers have investigated the association between body-related guilt or shame and selfie taking activities.

\section{Incremental Advances}

The present research will add to and extend existing knowledge on selfies. Kim and Chock's (2017) recent publication provides a foundation for Big Five personality research and selfie taking behaviors. While our work relating to personal- 
ity and the selfie was not intended to be a replication of their research, the findings we obtain will be useful in determining the robustness of their results. Furthermore, no published research has examined the relationship between typical selfie behaviors and facets of body image. This study will serve to address this gap. Finally, our study is the first to compare those who take selfies and those who do not. Such comparative work may elucidate intriguing differences in personality between the two groups.

\subsection{Hypotheses}

Extrapolating from the available literature on the personality correlates of SNS users, especially in terms of their photo activity, the following hypotheses were generated: 1) Extraversion and Neuroticism will correlate positively with number of selfies taken; 2) Social physique anxiety (SPA) and body-related shame will correlate negatively with the number of selfies taken; 3) engagement in selfie-editing will correlate positively with Neuroticism, Vanity, and SPA; and 4) those who take selfies will evidence lower levels of SPA and body-related shame and higher levels of vanity than those who do not take selfies. No specific hypotheses were formulated for body-related guilt (i.e., given its self-reparative focus, two possible outcomes seemed plausible: individuals higher in guilt may take selfies but spend greater time editing them prior to uploading the images or they may avoid taking selfies until they achieve a body that they deem suitable for "display").

\section{Method}

\subsection{Participants}

Two hundred and thirty-five (52 males; 183 females) individuals between the ges of 18 and $60(M=25$ years, $S D=9.31)$ participated in this study. The ethnic breakdown of this sample was Caucasian (85\%) followed by smaller proportions of Asian (5\%), Polynesian/Pacific Islanders (3\%), East Indian (2\%), Aboriginal (1\%), Hispanic (1\%), and Middle Eastern (1\%) persons. The overall sample was further split into two groups: those indicating they had taken selfies $(n=193)$ and those indicating they had not taken selfies $(n=42)$. The selfie group was comprised of 153 females, and 40 males ranging from 18 to 60 ( $M=25$ years, $S D$ $=9.20$ ) years of age. Additionally, this subsample was predominantly Caucasian (84\%). The non-selfie group consisted of 12 males and 30 females between the ages of 18 and $58(M=27$ years, $S D=9.78)$. The majority of this group was also Caucasian (88\%).

\subsection{Measures}

Body and Appearance Self-Conscious Emotions Scale (BASES; Castonguay et al., 2014). This instrument consists of 24 items in total, distributed evenly across 4 subscales: authentic pride, hubristic pride, guilt, and shame. Authentic pride may be defined as a positively valenced self-conscious emotion elicited by spe- 
cific and controllable behaviors that satisfy an internalized social standard relating to facets of the physical self (e.g., "Proud of the effort I place on maintaining my appearance"). Hubristic pride is a self-conscious emotion characterized by a positive feeling elicited from global and uncontrollable attributes of the physical self that satisfy an internalized social standard (e.g., "Proud that I am great-looking person"). Guilt may be viewed as a self-conscious emotion typified by a deleterious feeling evoked when unstable and controllable facets of the physical self fail to meet an internalized social standard (e.g., "Guilty that I do not do enough for my appearance"). Finally, shame reflects a self-conscious emotion characterized by unpleasantness/pain arising when stable, uncontrollable, and global facets of the physical self fail to fulfill an internalized social standard (e.g., "Ashamed that I am a person who is unattractive").

For each item, participants are asked to report "how often you have generally experienced the emotion" using a five-point Likert scale ( $1=$ never; 5 = always). Total subscale scores can range from 6 to 30, with higher scores denoting greater levels of the construct. Castonguay et al. (2014) found that the final 24 item version of the BASES scale evidenced good reliability and validity. In the current study, Cronbach's alpha coefficients were: authentic pride $(\alpha=.88,95 \% \mathrm{CI}=.86$ - .91), hubristic pride $(\alpha=.91,95 \% \mathrm{CI}=.89-.93)$, guilt $(\alpha=.90,95 \% \mathrm{CI}=.88$ - .92), and shame $(\alpha=.93,95 \% \mathrm{CI}=.91-.94)$.

Demographics. Eight items (e.g., “What is your age?’) were used to contextualize the sample. Of these, one served as a grouping variable: Have you ever taken a selfie? (yes/no) while another (In your own words, briefly describe what a selfie is) was included to ensure the integrity of the selfie group by gauging respondent familiarity with this term (A similar method was used by the Pew research group [2014]). One hundred percent of the sample accurately defined selfie; therefore, no exclusions had to be made.

Mini International Personality Item Pool (Mini IPIP; Donnellan, Oswald, Baird, \& Lucas, 2006). The 20-item Mini IPIP is a shortened version of the IPIP Five Factor Model (IPIP-FFM; Goldberg, 1999; Goldberg et al., 2006). It assesses the following personality traits: Extraversion (e.g., "I am the life of the party"), Agreeableness (e.g., "I am not interested in other people's problems"), Conscientiousness (e.g., "I like order"), Neuroticism (e.g., "I get upset easily"), and Openness (e.g., "I have a vivid imagination"). Participants rate each item using a five-point Likert scale ( $1=$ strongly disagree; $5=$ strongly agree). For each personality trait, total scores can range from 4 to 20, with higher scores suggesting the trait in question is more characteristic of the respondent. Available evidence (e.g., Baldasaro, Shanahan, \& Bauer, 2013; Donnellan et al., 2006) indicates that the Mini IPIP possesses satisfactory psychometric properties. In the current study, Cronbach's alpha coefficients were: Extraversion $(\alpha=.83,95 \% \mathrm{CI}=.79$ - .86); Agreeableness $(\alpha=.72,95 \% \mathrm{CI}=.66-.78)$; Conscientiousness $(\alpha=.72$, $95 \% \mathrm{CI}=.66-.77)$; Neuroticism $(\alpha=.75,95 \% \mathrm{CI}=.69-.80)$; and Openness $(\alpha$ $=.66,95 \% \mathrm{CI}=.59-.73)$. 
Selfie Taking Survey. This survey was comprised of 20 items that probe selfie taking behaviors and activities. For the purposes of the current study, 7 items were selected for analyses. The selected questions evaluated frequency of online posting (1 item: "How many selfies do you post in a month"), editing practices (2 items: e.g., "Do you edit your selfies before you post them"), sharing practices (3 items: e.g., "Do you take selfies with the intention of sharing them"), and types of selfie taken ( 1 item: "What kinds of selfies do you take"). These questions, in full, can be obtained from the corresponding author.

Social Physique Anxiety Scale (SPAS-7; Motl \& Conroy, 2000, 2001). The SPAS-7 measures individuals' concern about how their physical appearance will be evaluated (e.g., "When it comes to displaying my physique to others, I am a shy person"). The scale uses a five-point Likert scale ( $1=$ not at all characteristic; $5=$ extremely characteristic), with total scores ranging from 7 to 35 . Higher scores reflect greater levels of social physique anxiety. The existing research on the psychometric properties of the SPAS-7 indicate good scale reliability and validity (Motl \& Conroy, 2000, 2001) as well as temporal stability (Scott, Burke, Joyner, \& Brand, 2004). In the current study, scale score reliability for the SPAS-7 was $\alpha=.78,95 \% \mathrm{CI}=.73-.82$.

The Vanity Scale (Netemeyer et al., 1995). The present study used two of the four subscales from the Vanity Scale: Physical-Concern (PC; 5 items) and Physical-View (PV; 6 items). Both subscales reflect physical vanity, which Netemeyer et al. (1995) define as "an excessive concern for and/or a positive (and, perhaps, inflated) view of one's physical appearance" (p. 612). Items illustrative of these subscales are: "The way I look is extremely important to me" (PC) and "I am a very good-looking individual" (PV). A seven-point Likert scale is used for the $\mathrm{PC}$ and PV ( $1=$ strongly disagree; 7 = strongly agree). Total subscale scores can range from 5 to 35 and 6 to 42, respectively, with higher scores representing greater levels of physical vanity. Available research suggests that the Vanity Scale is psychometrically sound (e.g., Durvasula, Lysonski, \& Watson, 2001). In the current study, Cronbach's alpha coefficients were: $\mathrm{PC}=.89(95 \% \mathrm{CI}=.87-.91)$; $\mathrm{PV}=.92(95 \% \mathrm{CI}=.91-.94)$.

\subsection{Procedure}

An online questionnaire was constructed using FluidSurveys.com, which allowed for the generation of a unique URL to facilitate respondent access. Online advertisements and physical bulletins placed throughout the researchers' university were used to make prospective respondents aware of the study. In addition, social media such as Facebook were used for chain-referral recruitment.

Once individuals had accessed the questionnaire, they were prompted for consent before being able to proceed. All participants were asked to complete the personality, social physique anxiety, guilt, shame, and vanity measures. Based on their response to the item "Have you ever taken a selfie?," they were directed to either the selfie or non-selfie taking portion of the questionnaire. 


\subsection{Data Analysis}

Coinciding with many studies in the field of psychology (e.g., Keselman et al., 1998; Micceri, 1989) and with previous selfie research (e.g., Sorokowska et al., 2016), many of our variables had non-normal distributions. Thus, for all of the correlational analyses conducted in this study, Spearman's rho was used as it remains fairly accurate and powerful in the face of departures from normality (de Winter, Gosling, \& Potter, 2016; Field, 2005; Fowler, 1987). Similarly, Welch's $F$ test was selected for group comparisons as it has been shown to be a robust measure of group differences when data violate parametric assumptions (Cribbie, Fiksenbaum, Keselman, \& Wilcox, 2012; Rusticus \& Lovato, 2014; Tomarken \& Serlin, 1986).

\section{Results}

Bivariate relationships were examined between personality, body image, and selfie taking behaviors (see Table 1). Partial support was obtained for Hypothesis 1. Extraversion but not Neuroticism, correlated positively with the number of selfies taken per month. Contrary to Hypothesis 2, neither social physique anxiety nor body-related shame correlated with the number of selfies taken per month. Correlation coefficients provided support for Hypothesis 3. Congruent with our prediction, Neuroticism, vanity (physical concern facet only), and SPA correlated positively with the amount of time spent editing selfies and with the number of times a selfie was taken prior to being uploaded. No predictions were generated for body-related guilt and selfie taking. However, statistically significant positive associations were observed between guilt and number of selfies taken per month as well as all indices of editing behavior (i.e., amount of time spent editing and number of times a selfie was taken before getting uploaded).

To test the fourth hypothesis, comparing those who do versus those who do not take selfies, four one-way analyses of variance (ANOVAs) with Welch's $F$ correction were conducted. Contrary to our prediction, participants reporting that they took selfies did not evidence lower levels of social physique anxiety or body shame. However, congruent with our prediction, selfie takers evidenced greater levels of physical concern, a facet of vanity, than did non-selfie takers (see Table 2 for means and Welch's $F$ ).

\section{Discussion}

The findings of the present study can be broken down into two main themes: 1) correlates of selfie taking (ST) behavior; and, 2) group differences between STs and non-selfie takers (NSTs). As predicted, ST behavior was significantly associated with several of the Big Five personality traits, vanity, and facets of negative body image. Furthermore, group differences emerged between STs and NSTs in the domain of vanity.

Several of the Big Five indicators of personality correlated significantly with selfie taking behaviors. These findings were largely in keeping with the previous 
Table 1. Spearman Rho correlations among key variables.

\begin{tabular}{lccc}
\hline \multirow{2}{*}{ Variable } & \multicolumn{3}{c}{ Key selfie behavior } \\
\cline { 2 - 4 } Extraversion & Number per Month & Editing Time & Number of Takes \\
Neuroticism & $.149^{*}$ & .003 & -.075 \\
Agreeableness & .046 & $.174^{*}$ & $.287^{* *}$ \\
Openness & -.041 & .032 & .075 \\
Conscientiousness & -.007 & .032 & -.133 \\
BASES Shame & .016 & .007 & $-.181^{*}$ \\
BASES Guilt & .114 & $.152^{*}$ & $.243^{* *}$ \\
SPA & $.222^{* *}$ & $.183^{*}$ & $.238^{* *}$ \\
Physical View (PV) & .082 & $.248^{* *}$ & $.296^{* *}$ \\
Physical Concern (PC) & .123 & .091 & .054 \\
\hline
\end{tabular}

Note: BASES = Body and Appearance Self-Conscious Emotions Scale; SPA = social physique anxiety; For all scales, higher scores indicate a greater endorsement of the construct measured; Significant values are bolded. ${ }^{\star} p<.05 ;{ }^{* *} p<.01$.

Table 2. Summary of one-way ANOVA comparisons of selfie (ST) and non-selfie takers (NST).

\begin{tabular}{ccccccc}
\hline & \multicolumn{5}{c}{ Mean } & \multicolumn{3}{c}{ ANOVA } \\
\hline & ST & NST & DF1 & DF2 & Welch's $F$ & $P$ \\
\hline PC & 20.56 & 17.62 & 1 & 52.00 & 5.27 & $.026^{*}$ \\
PV & 21.83 & 20.98 & 1 & 55.34 & .43 & .52 \\
SPA & 19.17 & 19.33 & 1 & 56.25 & .03 & .87 \\
BASES Shame & 14.55 & 13.22 & 1 & 57.13 & 1.92 & .17 \\
\hline
\end{tabular}

Note: $p<.05$.

work of Kim and Chock (2017). Namely, Extraversion exhibited a positive relationship with the number of selfies posted per month, Neuroticism was not associated with selfie posting frequency, greater levels of Conscientiousness were related to less editing behavior (i.e., a priori editing), and Openness was not related to any selfie taking behaviors. However, a few departures from the findings of Kim and Chock (2017) were noted. Firstly, in the present study, greater endorsement of Neuroticism was related to a greater degree of editing behavior. Secondly, general editing frequency did not exhibit a relationship with Conscientiousness. Lastly, Agreeableness did not exhibit any associations with the selfie behaviors.

Our findings support previous research suggesting a link between vanity and selfie behaviors (Sorokowski et al., 2015). However, we deviated from past scholarship in a number of ways. Firstly, vanity has been shown to be composed of two facets (i.e., physical concern and physical view: Netemeyer et al., 1995) and we used these instead of a generalized measure. Through this lens, physical concern was found to be positively related to all selfie taking behaviors. Secondly, 
comparisons between selfie takers and non-selfie takers indicated that only physical concern differed significantly between the two groups. Physical concern is characterized by preoccupation with the body. These thoughts and perceptions do not have any particular valence; rather, they are general cognitive investments in one's physical appearance. On the other hand, no significant difference was noted between the two groups on the dimension of physical view. This facet of vanity denotes self-aggrandizing thoughts and perceptions regarding one's appearance. Thus, the pattern of results suggest that the role of vanity may be capturing the influence of constructs relating to negative body image (i.e., body surveillance: Knauss, Paxton, \& Alsaker, 2008; McKinley \& Hyde, 1996) rather than the characteristics more clearly attributable to the overall construct of narcissism.

Emotional aspects of body image presented a mixture of results. In keeping with our predictions, body-related shame and SPA were positively related to engaging in selfie editing behaviors. Unexpectedly, neither variable showed a negative association with frequency of selfie posting. Mechanisms of self-presentation offer a possible explanation for these results. Editing practices relating to selfie posting may attenuate posting inhibitions through the reduction of anticipated negative peer appraisals. There is a growing body of literature showing the prevalence of impression management strategies employed on SNSs (e.g., Seidman, 2013). Online photo editing practices are undertaken for a variety of reasons, all commonly associated with perceived social benefit (e.g., gaining popularity: Siibak, 2009; mate selection: Fox \& Rooney, 2015). Through the use of editing practices, individuals can ensure a positive representation of themselves in these online contexts. Thus, the slightly positive correlation for selfie posting frequency shown for both body-related shame and SPA may reflect some aspect of disinhibition relating to access and use of editing tools in the context of posting selfies.

Additionally, we had assumed that individuals avoiding engagement in selfie taking might evidence greater social physique anxiety and body-related shame than their selfie taking counterparts; however, neither prediction was supported. This would suggest that aspects of negative body image may not explain the motivations behind choosing not to take selfies. As alluded to above, positive self-presentation could be achieved easily through photo editing behaviors. Future research should explore the motivations to avoid selfie taking in greater depth.

While specific hypotheses were not generated for body-related guilt, there were several statistically significant findings. Body-related guilt correlated positively with all indicators of selfie taking (i.e., as guilt increased so, too, did the number of selfies taken, and the amount of time spent editing selfies prior to upload). Since body-related guilt is thought to be characterized by the failure to achieve and/or the neglect of goals associated with appearance (Castonguay et al., 2014), it is possible that photo editing behaviors are used to assuage this negative feeling through the artificial creation of an ideal self. Within the context of 
negative body image, posting pictures of oneself on a platform that facilitates viewing frequency and viewer traffic seems to be counterintuitive. However, past research suggests that SNSs enable communication with potential sources of support (e.g., Frison \& Eggermont, 2015). In the case of body-related guilt and selfie taking, individuals may be using the selfie as a medium to elicit sympathetic feedback and counteract their negative body view.

This study possesses several limitations. The first is the correlational nature of the research which precludes making causal inferences. Second, while the recruitment methods were designed to be inclusive, the sample still predominantly consisted of young Caucasian females thereby limiting the generalizability of the results. Third, due to a technical error, NSTs had to complete the entire questionnaire package, including the ST measure, instead of being redirected straight to the NST portion of the survey. This may have heightened fatigue among the NST group which, in turn, may have contributed to their smaller sample size.

Research on the selfie and its many facets is just emerging; thus, there are myriad directions for future inquiry. One such avenue could be the employment of theoretically derived frameworks to examine the potential relationship between selfies and SNSs. For example, Uses and Gratifications (U\&G) theory is commonly applied to a wide spectrum of media and its consumers. The premise of $\mathrm{U} \& \mathrm{G}$ theory is that media users select and use media based on satiating their individual sets of needs and/or wants (e.g., Ruggiero, 2000). Thus, U\&G research examines psychological and social elements that comprise various user populations (i.e., audiences) and how these factors relate to types or features of media with which users engage. U\&G has been applied to the study of SNS and its users to shed light on the motivations that drive usage of certain SNSs sites as well as to understand the psychological composition of these groups (e.g., Pai \& Arnott, 2013; Raacke \& Bonds-Raacke, 2008). Use of U\&G theory in the context of social media could potentially provide insights into the psychological profiles of SNS users that are involved with selfie-taking and other assorted linked behaviors.

Additionally, given the finding of a positive association between selfie taking, negative facets of body image (i.e., body-related guilt and social physique anxiety), and appearance preoccupation, future research may wish to explore the extent to which selfie taking relates to eating disorders. This idea can be extrapolated thusly: the research on the association between facets of negative body image and disordered eating behaviors is extensive; the general trend within this research indicates that facets of negative body image are typically positively correlated to the presence and/or severity of disordered eating behaviors (Larsen, Strandburg-Larsen, Micali, \& Anderson, 2015). Similarly, there exists a large body of research on the relationship between negative body image and SNSs (Holland \& Tiggemann, 2016). As the selfie appears to be related to certain facets of negative body image and is strongly connected to SNS and SNS-related behaviors. Therefore, it is likely that selfies and selfie taking behaviors may be related to disordered eating behaviors in some way. In sum, it may be prudent to 
determine how selfies may influence eating disorder symptomology as there are no current studies available within this research sector.

Lastly, the current study considered selfie behavior by collapsing all SNSs into a single category. This makes the assumption that each SNS is fundamentally similar when, in fact, there may be pronounced differences among them (i.e., demographics of users, functionality, and mobility). As a result, selfie behavior and motivation may vary appreciably according to the type of SNS (e.g., Instagram, Facebook, Snapchat) for which the selfies are intended. Due to this, future research should attempt to understand selfie posting behavior and its correlates across popular SNSs.

\section{Conclusion}

The current study provides additional information on the selfie phenomenon and adds to the growing body of research on the topic. Several links between selfie taking behaviors and study variables such as dimensions of the Big Five factors of personality, body image and appearance related variables, and group differences (i.e., selfie takers versus non-selfie takers) were found. These initial connections are important because the selfie is emerging as a fairly ubiquitous form of communication and, at the moment, little scientific exploration has been initiated. Due to the exploratory nature of this data, there is ample opportunity to research the selfie and its plethora of potential correlates. It is our hope that this study will stimulate further research interest into the selfie phenomenon.

\section{Acknowledgements}

This study was conducted with the support of a Social Sciences and Humanities Research Council of Canada (SSHRC) Insight Grant (\#435-2016-1485) awarded to the third and fourth authors.

\section{References}

Amichai-Hamburger, Y., \& Vinitzky, G. (2010). Social Network Use and Personality. Computers in Human Behavior, 26, 1289-1295. https://doi.org/10.1016/j.chb.2010.03.018

Ashton, M. C., \& Lee, K. (2009). The HEXACO-60: A Short Measure of the Major Dimensions of Personality. Journal of Personality Assessment, 91, 340-345. https://doi.org/10.1080/00223890902935878

Baiocco, R., Chirumbolo, A., Bianchi, D., Ioverno, S., Morelli, M., \& Nappa, M. R. (2017) How HEXACO Personality Traits Predict Different Selfie-Posting Behaviors among Adolescents and Young Adults. Frontiers in Psychology, 7, 1-9. https://doi.org/10.3389/fpsyg.2016.02080

Baldasaro, R. E., Shanahan, M. J., \& Bauer, D. J. (2013). Psychometric Properties of the Mini-IPIP in a Large, Nationally Representative Sample of Young Adults. Journal of Personality Assessment, 95, 74-84. https://doi.org/10.1080/00223891.2012.700466

Barry, C. T., Doucette, H., Loflin, D. C., Rivera-Hudson, N., \& Herrington, L. L. (2017). Let me Take a Selfie. Psychology of Popular Media Culture, 6, 48-60. 
https://doi.org/10.1037/ppm0000089

Baumeister, R. F., Stillwell, A. M., \& Heatherton, T. F. (1994). Guilt: An Interpersonal Approach. Psychological Bulletin, 115, 243-267.

https://doi.org/10.1037/0033-2909.115.2.243

Brunet, J., Sabiston, C. M., Dorsch, K. D., \& McCreary, D. R. (2010). Exploring a Model Linking Social Physique Anxiety, Drive for Muscularity, Drive for Thinness, and Self-Esteem among Adolescent Boys and Girls. Body Image, 7, 137-142. https://doi.org/10.1016/j.bodyim.2009.11.004

Castonguay, A. L., Pila, E., Wrosch, C., \& Sabiston, C. M. (2015). Body-Related Self-Conscious Emotions Relate to Physical Activity Motivation and Behavior in Men. American Journal of Men's Health, 9, 209-221. https://doi.org/10.1177/1557988314537517

Castonguay, A. L., Sabiston, C. M., Crocker, P. R., \& Mack, D. E. (2014). Development and Validation of the Body and Appearance Self-Conscious Emotions Scale (BASES). Body Image, 11, 126-136. https://doi.org/10.1016/j.bodyim.2013.12.006

Costa, P. T., \& McCrae, R. R. (1992). Normal Personality Assessment in Clinical Practice: The NEO Personality Inventory. Psychological Assessment, 4, 5-13. https://doi.org/10.1037/1040-3590.4.1.5

Cribbie, R. A., Fiksenbaum, L, Keselman, H. J., \& Wilcox, R. R. (2012). Effect of Non-Normality on Test Statistics for One-Way Independent Groups Designs. British Journal of Mathematical and Statistical Psychology, 65, 56-73. https://doi.org/10.1111/j.2044-8317.2011.02014.x

de Winter, J. C., Gosling, S. D., \& Potter, J. (2016). Comparing the Pearson and Spearman Correlation Coefficients across Distributions and Sample Sizes: A Tutorial Using Simulations and Empirical Data. Psychological Methods, 21, 273. https://doi.org/10.1037/met0000079

Donnellan, M. B., Oswald, F. L., Baird, B. M., \& Lucas, R. E. (2006). The Mini-IPIP Scales: Tiny-Yet-Effective Measures of the Big Five Factors of Personality. Psychological As sessment, 18, 192-203. https://doi.org/10.1037/1040-3590.18.2.192

Durvasula, S., Lysonski, S., \& Watson, J. (2001). Does Vanity Describe Other Cultures? A Cross-Cultural Examination of the Vanity Scale. Journal of Consumer Affairs, 35, 180-199. https://doi.org/10.1111/j.1745-6606.2001.tb00108.x

Eftekhar, A., Fullwood, C., \& Morris, N. (2014). Capturing Personality from Facebook Photos and Photo-Related Activities: How Much Exposure Do You Need? Computers in Human Behavior, 37, 162-170. https://doi.org/10.1016/j.chb.2014.04.048

Field, A. (2005). Discovering Statistics Using SPSS: And Sex, Drugs and Rock " $n$ " Roll (2nd ed.). London: Sage.

Fowler, R. L. (1987). Power and Robustness in Product-Moment Correlation. Applied Psychological Measurement, 11, 419-428. https://doi.org/10.1177/014662168701100407

Fox, J., \& Rooney, M. C. (2015). The Dark Triad and Trait Self-Objectification as Predictors of Men's Use and Self-Presentation Behaviors on Social Networking Sites. Personality and Individual Differences, 76, 161-165. https://doi.org/10.1016/j.paid.2014.12.017

Frison, E., \& Eggermont, S. (2015). The Impact of Daily Stress on Adolescents' Depressed Mood: The Role of Social Support Seeking through Facebook. Computers in Human Behavior, 44, 315-325. https://doi.org/10.1016/j.chb.2014.11.070

Goldberg, L. R. (1999). A Broad-Bandwidth, Public Domain, Personality Inventory Mea- 
suring the Lower-Level Facets of Several Five-Factor Models. Personality Psychology in Europe, 7, 7-28.

http://projects.ori.org/lrg/PDFs_papers/A\%20broad-bandwidth\%20inventory.pdf

Goldberg, L. R., Johnson, J. A., Eber, H. W., Hogan, R., Ashton, M. C., Cloninger, C. R., \& Gough. H. G. (2006). The International Personality Item Pool and the Future of Public Domain Personality Measures. Journal of Research in Personality, 40, 84-96. https://doi.org/10.1016/j.jrp.2005.08.007

Guo, M., Liu, R. D., Ding, Y., Hu, B., Zhen, R., Liu, Y., \& Jiang, R. (2018). How Are Extraversion, Exhibitionism, and Gender Associated with Posting Selfies on WeChat Friends' Circle in Chinese Teenagers? Personality and Individual Differences, 127, 114-116. https://doi.org/10.1016/j.paid.2018.01.042

Holland, G., \& Tiggemann, M. (2016). A Systematic Review of the Impact of the Use of Social Networking Sites on Body Image and Disordered Eating Outcomes. Body Image, 17, 100-110. https://doi.org/10.1016/j.bodyim.2016.02.008

Katz, J. E., \& Crocker, E. T. (2015). Selfies and Photo Messaging as Visual Conversation: Reports from the United States, United Kingdom and China. International Journal of Communication, 9, 1861-1872.

Keselman, H. J., Huberty, C. J., Lix, L. M., Olejnik, S., Cribbie, R. A., Donahue, B. et al. (1998). Statistical Practices of Educational Researchers: An Analysis of Their ANOVA, MANOVA, and ANCOVA Analyses. Review of Educational Research, 68, 350-386. https://doi.org/10.3102/00346543068003350

Kim, J. W., \& Chock, T. M. (2017). Personality Traits and Psychological Motivations Predicting Selfie Posting Behaviors on Social Networking Sites. Telematics and Informatics, 34, 560-571. https://doi.org/10.1016/j.tele.2016.11.006

Knauss, C., Paxton, S. J., \& Alsaker, F. D. (2008). Body Dissatisfaction in Adolescent Boys and Girls: Objectified Body Consciousness, Internalization of the Media Body Ideal and Perceived Pressure from Media. Sex Roles, 59, 633-643.

Larsen, P., Strandberg-Larsen, K., Micali, N., \& Andersen, A. (2015). Parental and Child Characteristics Related to Early-Onset Disordered Eating: A Systematic Review. Harvard Review of Psychiatry, 23, 395-412.

Lee, E., Ahn, J., \& Kim, Y. J. (2014). Personality Traits and Self-Presentation at Facebook. Personality and Individual Differences, 69, 162-167. https://doi.org/10.1016/j.paid.2014.05.020

McCain, J. L., Borg, Z. G., Rothenberg, A. H., Churillo, K. M., Weiler, P., \& Campbell, W. K. (2016). Personality and Selfies: Narcissism and the Dark Triad. Computers in Human Behavior, 64, 126-133. https://doi.org/10.1016/j.chb.2016.06.050

McCrae, R. R., \& Costa, P. T. (1997). Personality Trait Structure as a Human Universal. American Psychologist, 52, 509-516. https://doi.org/10.1037/0003-066X.52.5.509

McKinley, N. M., \& Hyde, J. S. (1996). The Objectified Body Consciousness Scale: Development and Validation. Psychology of Women Quarterly, 20, 181-215. https://doi.org/10.1111/j.1471-6402.1996.tb00467.x

Mehdizadeh, S. (2010). Self-Presentation 2.0: Narcissism and Self-Esteem on Facebook. Cyberpsychology, Behavior, and Social Networking, 13, 357-364. https://doi.org/10.1089/cyber.2009.0257

Micceri, T. (1989). The Unicorn, the Normal Curve, and Other Improbable Creatures. Psychological Bulletin, 105, 156-166. https://doi.org/10.1037/0033-2909.105.1.156

Motl, R. W., \& Conroy, D. E. (2000). Validity and Factorial Invariance of the Social Physique Anxiety Scale. Medicine \& Science in Sports \& Exercise, 32, 1007-1017. 
https://doi.org/10.1097/00005768-200005000-00020

Motl, R. W., \& Conroy, D. E. (2001). The Social Physique Anxiety Scale: Cross Validation, Factorial Invariance, and Latent Mean Structure. Measurement in Physical Education and Exercise Science, 5, 81-95. https://doi.org/10.1207/S15327841MPEE0502_2

Netemeyer, R. G., Burton, S., \& Lichtenstein, D. R. (1995). Trait Aspects of Vanity: Measurement and Relevance to Consumer Behavior. Journal of Consumer Research, 21, 612-626. https://doi.org/10.1086/209422

Ong, E. Y., Ang, R. P., Ho, J. C., Lim, J. C., Goh, D. H., Lee, C. S., \& Chua, A. Y. (2011). Narcissism, Extraversion and Adolescents' Self-Presentation on Facebook. Personality and Individual Differences, 50, 180-185. https://doi.org/10.1016/j.paid.2010.09.022

Pai, P., \& Arnott, D. C. (2013). User Adoption of Social Networking Sites: Eliciting Uses and Gratifications through a Means-End Approach. Computers in Human Behavior, 29, 1039-1053. https://doi.org/10.1016/j.chb.2012.06.025

Pew Research Center (2014). Generations and Selfies [Data File]. http://www.pewsocialtrends.org/2014/03/07/millennials-in-adulthood/sdt-next-americ a-03-07-2014-3-13/

Pincus, A. L., Ansell, E. B., Pimentel, C. A., Cain, N. M., Wright, A. G., \& Levy, K. N. (2009). Initial Construction and Validation of the Pathological Narcissism Inventory. Psychological Assessment, 21, 365-379. https://doi.org/10.1037/a0016530

Pruzinsky, T., \& Cash, T. F. (2002). Understanding Body Images: Historical and Contemporary Perspectives. In T. F. Cash, \& T. Pruzinsky (Eds.), Body Image: A Handbook of Theory, Research, and Clinical Practice (pp. 3-12). New York: Guilford Press.

Raacke, J., \& Bonds-Raacke, J. (2008). Myspace and Facebook: Applying the Uses and Gratifications Theory to Exploring Friend-Networking Sites. CyberPsychology \& Behavior, 11, 169-174. https://doi.org/10.1089/cpb.2007.0056

Raskin, R., \& Terry, H. (1988). A Principal-Components Analysis of the Narcissitic Personality Inventory and Further Evidence of Its Construct Validity. Journal of Personality and Social Psychology, 54, 890-902. https://doi.org/10.1037/0022-3514.54.5.890

Ross, C., Orr, E. S., Sisic, M., Arseneault, J. M., Simmering, M. G., \& Orr, R. R. (2009). Personality and Motivations Associated with Facebook Use. Computers in Human Behavior, 25, 578-586. https://doi.org/10.1016/j.chb.2008.12.024

Ruggiero, T. E. (2000). Uses and Gratifications Theory in the 21st Century. Mass Communication \& Society, 3, 3-37. https://doi.org/10.1207/S15327825MCS0301_02

Rusticus, S. A., \& Lovato, C. Y. (2014). Impact of Sample Size and Variability on the Power and Type I Error Rates of Equivalence Tests: A Simulation Study. Practical Assessment, Research \& Evaluation, 19, 1-10. http://pareonline.net/getvn.asp?v=19\&n=11

Ryan, T., \& Xenos, S. (2011). Who Uses Facebook? An Investigation into the Relationship between the Big Five, Shyness, Narcissism, Loneliness, and Facebook Usage. Computers in Human Behavior, 27, 1658-1664. https://doi.org/10.1016/j.chb.2011.02.004

Sabiston, C. M., Pila, E., Pinsonnault-Bilodeau, G., \& Cox, A. E. (2014). Social Physique Anxiety Experiences in Physical Activity: A Comprehensive Synthesis of Research Studies Focused on Measurement, Theory, and Predictors and Outcomes. International Review of Sport and Exercise Psychology, 7, 158-183.

https://doi.org/10.1080/1750984X.2014.904392

Scott, L. A., Burke, K. L., Joyner, A. B., \& Brand, J. S. (2004). Examining the Stability of the 7-Item Social Physique Anxiety Scale Using a Test-Retest Method. Measurement in Physical Education Exercise Science, 8, 57-62.

https://doi.org/10.1207/s15327841mpee0802_1 
Seidman, G. (2013). Self Presentation and Belonging on Facebook: How Personality Influences Social Media Use and Motivations. Personality and Individual Differences, 54, 402-407. https://doi.org/10.1016/j.paid.2012.10.009

Siibak, A. (2009). Constructing the Self through the Photo Selection-Visual Impression Management on Social Networking Websites. Cyberpsychology: Journal of Psychosocial Research on Cyberspace, 3, Article 1. https://cyberpsychology.eu/article/view/4218

Silfver, M. (2007). Coping with Guilt and Shame: A Narrative Approach. Journal of Moral Education, 36, 169-183. https://doi.org/10.1080/03057240701325274

Sorokowska, A., Oleszkiewicz, A., Frackowiak, T., Pisanski, K., Chmiel, A., \& Sorokowski, P. (2016). Selfies and Personality: Who Posts Self-Portrait Photographs? Personality and Individual Differences, 90, 119-123. https://doi.org/10.1016/j.paid.2015.10.037

Sorokowski, P., Sorokowska, A., Oleszkiewicz, A., Frackowiak, T., Huk, A., \& Pisanski, K. (2015). Selfie Posting Behaviors Are Associated with Narcissism among Men. Personality and Individual Differences, 85, 123-127. https://doi.org/10.1016/j.paid.2015.05.004

Sung, Y., Lee, J. A., Kim, E., \& Choi, S. M. (2016). Why We Post Selfies: Understanding Motivations for Posting Pictures of Oneself. Personality and Individual Differences, 97, 260-265. https://doi.org/10.1016/j.paid.2016.03.032

Tangney, J. P., \& Tracy, J. L. (2012). Self-Conscious Emotions. In M. Leary, \& J. P. Tangney (Eds.), Handbook of Self and Identity (2nd ed., Vol. 2, pp. 446-478). New York: Guilford Press.

Tiggemann, M. (2014). The Status of Media Effects on Body Image Research: Commentary on Articles in the Themed Issue on Body Image and Media. Media Psychology, 17, 127-133. https://doi.org/10.1080/15213269.2014.891822

Tomarken, A. J., \& Serlin, R. C. (1986). Comparison of ANOVA Alternatives under Variance Heterogeneity and Specific Noncentrality Structures. Psychological Bulletin, 99, 90-99. https://doi.org/10.1037/0033-2909.99.1.90

Weiser, E. B. (2015). \#Me: Narcissism and Its Facets as Predictors of Selfie-Posting Frequency. Personality and Individual Differences, 86, 477-481.

https://doi.org/10.1016/j.paid.2015.07.007 